04

\title{
Запись поляризационных голограмм в полимерных пленках с азокрасителями и азополимерами
}

\author{
(c) Н.А. Давиденко ${ }^{1}$, И.И. Давиденко ${ }^{1}$, В.В. Кравченко ${ }^{2}$, Е.В. Мокринская ${ }^{1}$, В.А. Павлов ${ }^{1}$, \\ И.А. Савченко ${ }^{1}$, В.В. Тарасенко ${ }^{1}$, Н.Г. Чуприна ${ }^{1}$ \\ ${ }^{1}$ Киевский национальный университет имени Тараса Шевченко, \\ 01601 Киев, Украина \\ ${ }^{2}$ Институт физико-органической химии и углехимии им. Л.М.Литвиненко НАН Украины, \\ 02160 Киев, Украина \\ e-mail: ndav@univ.kiev.ua
}

Поступила в редакцию 15.01.2019 г.

В окончательной редакции 15.01.2019 г.

Принято к публикации 04.06.2019 г.

На основе полимеров с добавками азокрасителей как хромофоров и азополимеров с ковалентно связанными такими же хромофорами созданы регистрирующие среды для поляризационной голографии и исследованы их свойства при записи голограмм плоского волнового фронта с параллельной и перпендикулярной поляризацией записывающих лучей. Обнаружено, что дифракционная эффективность и время хранения голограмм значительно больше в регистрирующих средах с пленками азополимеров по сравнению с полимерными твердыми растворами азокрасителей. В последнем случае энергия света при экспонировании голограмм расходуется только на транс-цис-изомеризацию молекул азокрасителей и не происходит деформация полимерных цепей с образованием поверхностного рельефа полимерной пленки. Поэтому для динамической поляризационной голографии предпочтительно использование регистрирующих сред на основе твердых растворов азокрасителей.

DOI: $10.21883 /$ OS.2019.11.48517.26-19

\section{Введение}

Для создания регистрирующих сред (РС) в поляризационной голографии используются пленки полимерных композитов (ППК), в которых в качестве хромофоров применяют производные азобензола или родственные им соединения. Принцип записи голограмм в средах с азобензольными хромофорами основан на том, что при облучении линейно поляризованным светом из области поглощения транс-изомеров в этих пленках появляется фотоиндуцированная оптическая анизотропия (ФИА), которая вызвана процессами транс-цис-изомеризации азобензольных групп. Фотоизомеризация азобензольных хромофоров может вызвать конформационные изменения на молекулярном уровне, и в аморфных пленках могут образовывать устойчивые рельефы поверхности [1-13]. Такие РС позволяют получить высокие значения дифракционной эффективности голограмм, что имеет практическое применение, например в голографической интерферометрии [14-16]. В последнем случае записанные голограммы должны быть стабильными в течение длительного времени после их регистрации. Другое проявление поляризационной голографии динамическая поляризационная голография [17-22], в которой РС отликаются на записываемею интерференционную картину только во время экспозиции и „забывают“" о предшествующем цикле записи. В этом случае времена записи и релаксации голограммы должны быть как можно короче. Однако в литературе в недостаточной мере отражен вопрос оптимизации выбора фоточувствительных макромолекулярных структур для создания РС. Целью настоящей работы было экспериментальное сравнительное исследование кинетики записи и релаксации голограмм плоского волнового фронта в РС на основе полимеров с добавками азокрасителей и азополимеров с ковалентно связанными азохромофорами.

\section{Эксперимент}

Для исследований и приготовления ППК использовали азокрасители 4-метокси-4'-гидроксиазобензол $\left(\mathrm{azo}-\mathrm{OCH}_{3}\right)$ и 4-метил-4'-гидроксиазобензол $\left(\mathrm{azo}-\mathrm{CH}_{3}\right)$, которые вводили в полимерные матрицы. В качестве полимерных матриц были выбраны полиметилметакрилат (PMМА, образцы 1, $\mathbf{1}^{\prime}$ ), полиметакриловая кислота (РМАA, образцы 2, $\mathbf{2}^{\prime}$ ) и сополимер метакриловой кислоты с метилметакрилатом 3:1 (MAA-co-MМА, образцы $3, \mathbf{3}^{\prime}$ ), полученные методом радикальной (со)полимеризации в присутствии $1 \%$ mass. AIBN в качестве инициатора. Состав и структуры компонент ППК 1-3 и $\mathbf{1}^{\prime}-\mathbf{3}^{\prime}$ детализирован в таблице. ППК $\mathbf{1}$ и $\mathbf{1}^{\prime}$ приготавливали путем растворения исходных веществ в хлористом метилене, а ППК 2,3 и $\mathbf{2}^{\prime}, \mathbf{3}^{\prime}$ - в ДМФА в соотношении 10 mass.\% азокрасителя от массы полимера.

Для сравнения РС на основе ППК с твердыми растворами азокрасителей azo- $\mathrm{CH}_{3}$ и azo- $\mathrm{OCH}_{3}$ методом радикальной сополимеризации в присутствии 
Состав ППК и измеренные максимальные значения дифракционной эффективности $\eta_{\| \max }$ и $\eta_{\perp \max }$ в РС с ППК 1-4 и $\mathbf{1}^{\prime}-\mathbf{4}^{\prime}$ сразу после экспонирования в течение $2 \mathrm{~min}$

\begin{tabular}{|c|c|}
\hline 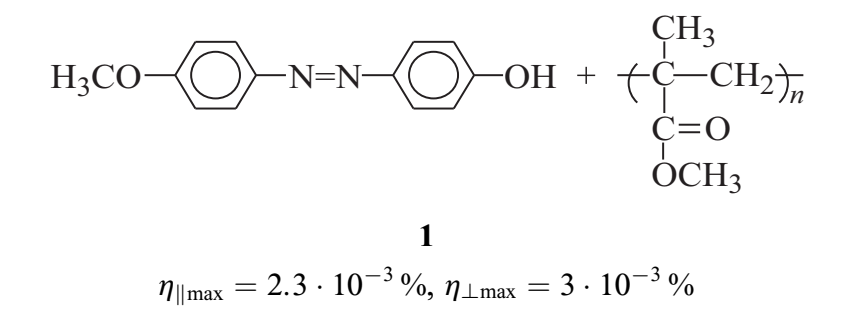 & 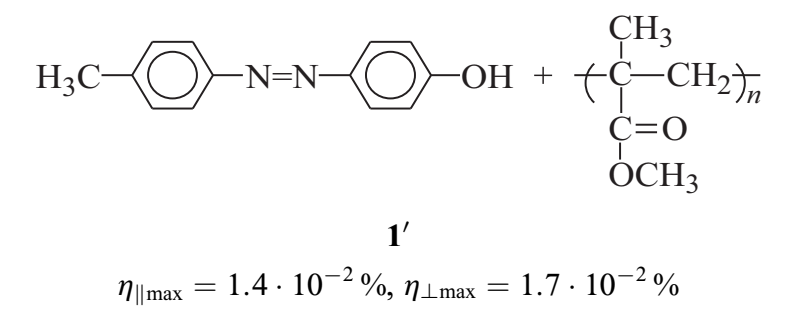 \\
\hline $\begin{array}{c}\mathrm{H}_{3} \mathrm{CO}-\mathrm{N}=\mathrm{N}-\mathrm{OH}+\underset{\substack{\mathrm{C}=\mathrm{O} \\
\mathrm{O}}}{\left.\stackrel{\mathrm{C}}{\mathrm{CH}}-\mathrm{CH}_{2}\right)_{k}} \\
\eta_{\| \max }=2.5 \cdot 10^{-3} \%, \eta_{\perp \max }=4.2 \cdot 10^{-3} \%\end{array}$ & $\begin{array}{c}\mathrm{H}_{3} \mathrm{C}-\mathrm{N}=\mathrm{N}-\underset{\substack{\mathrm{C} \\
\mathrm{O}}}{\left.+\underset{I}{\mathrm{C}}-\mathrm{CH}_{2}\right)_{k}} \\
\eta_{\| \max }=1.9 \cdot 10^{-2} \%, \eta_{\perp \max }=2.3 \cdot 10^{-2} \%\end{array}$ \\
\hline 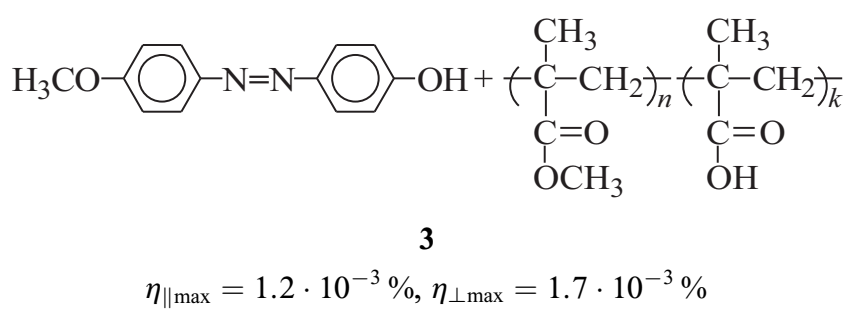 & 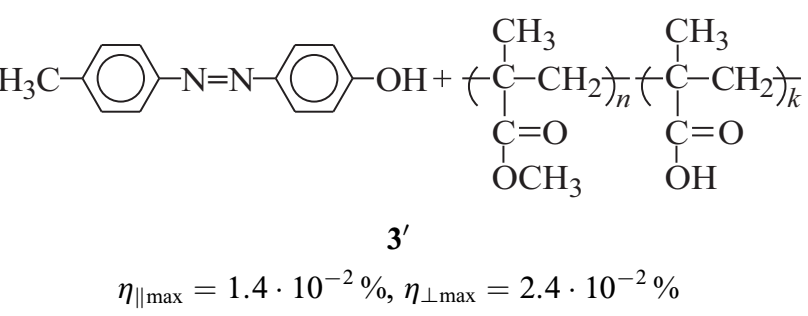 \\
\hline 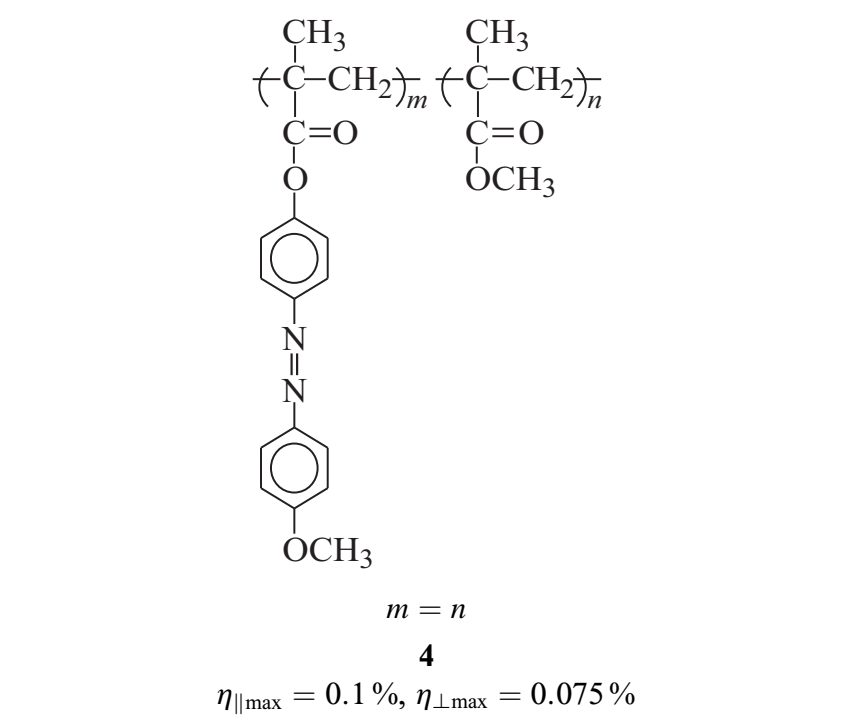 & $\eta_{\| \max }=0.56 \%, \eta_{\perp \max }=0.33 \%$ \\
\hline
\end{tabular}

$5 \%$ mass. AIBN в качестве инициатора были синтезированы метакриловые сополимеры с ММА $(1: 1)$, содержащие ковалентно связанные азохромофоры в боковой цепи: поли[4-((4'-метоксифенил)диазенил)фенилметакрилат-со-метилметакрилат] (MMA-co-azo-OCH 3 , образец 4) и поли[4-((4'-метилфенил)диазенил)фенилметакрилат-со-метилметакрилат] (MМA-co-azo- $\mathrm{CH}_{3}$, образец $\mathbf{4}^{\prime}$ ), структурные формулы которых представлены в таблице. Для приготовления ППК сополимеры $\mathbf{4}$ и $\mathbf{4}^{\prime}$ растворяли в хлористом метилене.
Состав и структуру синтезированных веществ идентифицировали методами элементного анализа, ${ }^{1} \mathrm{H}$ ЯМРи УФ спектроскопии. Элементный анализ полученных соединений проводили на CHNOS-элементном анализаторе Elementar Gmbh „Vario Micro Cube“. ${ }^{1} \mathrm{H}$ ЯMPспектры полученных веществ снимали на ${ }^{1} \mathrm{H}$ ЯМРспектрометре Varian „Mercury-400“ в ДМСО- $\mathrm{d}_{6}$ с внутренним стандартом тетраметилсиланом.

Для исследований приготавливали образцы РС со свободной поверхностью ППК, нанесенных на стеклянные 
подложки. ППК приготовляли путем полива подготовленных растворов $\mathbf{1}, 4$ и $\mathbf{1}^{\prime}, \mathbf{4}^{\prime}$ в хлористом метилене, а 2,3 и $\mathbf{2}^{\prime}, \mathbf{3}^{\prime}$ в диметилформамиде на стеклянные подложки, сушки в течение $24 \mathrm{~h}$ в термошкафу при температуре $80^{\circ} \mathrm{C}$. Толщина ППК $2-3 \mu \mathrm{m}$ измерена с помощью интерференционного микроскопа. Температура размягчения $T_{s}$ ППК, которую измеряли по известной методике [23], составляет $\sim 75 \pm 2{ }^{\circ} \mathrm{C}$.

В образцах РС со свободной поверхностью ППК записывали голограммы плоского волнового фронта с пространственной частотой $300 \mathrm{~mm}^{-1}$ при равной интенсивности света в объектном $\left(I_{1}\right)$ и опорном $\left(I_{2}\right)$ пучках. Использовали твердотельный лазер с диодной накачкой и удвоением частоты с $\lambda_{1}=532 \mathrm{~nm}$. Суммарная интенсивность света $I_{1}+I_{2}$ перед РС составляла $5 \cdot 10^{3} \mathrm{~W} / \mathrm{m}^{2}$. Запись голограмм проводили для параллельной $\left(\mathbf{e}_{1} \| \mathbf{e}_{2}\right)$ и перпендикулярной $\left(\mathbf{e}_{1} \perp \mathbf{e}_{2}\right)$ ориентации электрических векторов падающих объектной $\left(\mathbf{e}_{1}\right)$ и опорной $\left(\mathbf{e}_{2}\right)$ световых волн. Величину дифракционной эффективности $(\eta)$ голограммы определяли по общепринятой методике [24] как отношение интенсивности света в -1-м порядке дифракции к интенсивности опорного луча $I_{2}$ (он же восстанавливающий луч в процессе считывания) для параллельной $\left(\mathbf{e}_{1} \| \mathbf{e}_{2}\right)$ и перпендикулярной $\left(\mathbf{e}_{1} \perp \mathbf{e}_{2}\right)$ ориентации электрических векторов записывающих световых волн (соответственно как $\eta_{\|}$и $\left.\eta_{\perp}\right)$. Измеряли зависимости $\eta_{\|}(t)$ и $\eta_{\perp}(t)$ от времени $t$ после начала и завершения экспонирования голограммы. После достижения максимальной дифракционной эффективности (соответственно $\eta_{\| \max }$ и $\eta_{\perp \max }$ ) релаксацию голографического изображения отслеживали двумя способами: 1) выключали только объектный луч $\left(I_{1}=0\right)$ и непрерывно измеряли интенсивность света в -1-м порядке дифракции при включенном считывающем луче; 2) выключали оба записывающих луча $\left(I_{1}=0, I_{2}=0\right)$ и периодически на короткое время $\sim 1 \mathrm{~s}$ включали считывающий луч для измерения интенсивности света в $-1-\mathrm{M}$ порядке дифракции. Каждое новое измерение проводили на новом участке РС для исключения влияния предыдущего эксперимента (памяти о записи голограммы). Результаты измерений усредняли по 3-м идентичным образцам РС. Все измерения проведены при комнатной температуре $20^{\circ} \mathrm{C}$.

\section{Результаты и их обсуждение}

Для примера на рис. 1 представлены спектры оптической плотности ППК $\mathbf{1}$ и $\mathbf{1}^{\prime}$. Эти спектры аналогичны спектрам поглощения соответственно ППК $\mathbf{2 - 4}$ и $\mathbf{2}^{\prime}-\mathbf{4}^{\prime}$. Поглощение этих ППК определяется поглощением азохромофоров и поэтому незначительный батохромный сдвиг спектров при переходе от ППК c azo- $\mathrm{CH}_{3}$ к ППК c azo-OCH ${ }_{3}$ можно объяснить усилением акцепторных свойств заместителя $-\mathrm{OCH}_{3}$ в сравнении с $-\mathrm{CH}_{3}$, так и увеличением дипольного момента азохромофоров.

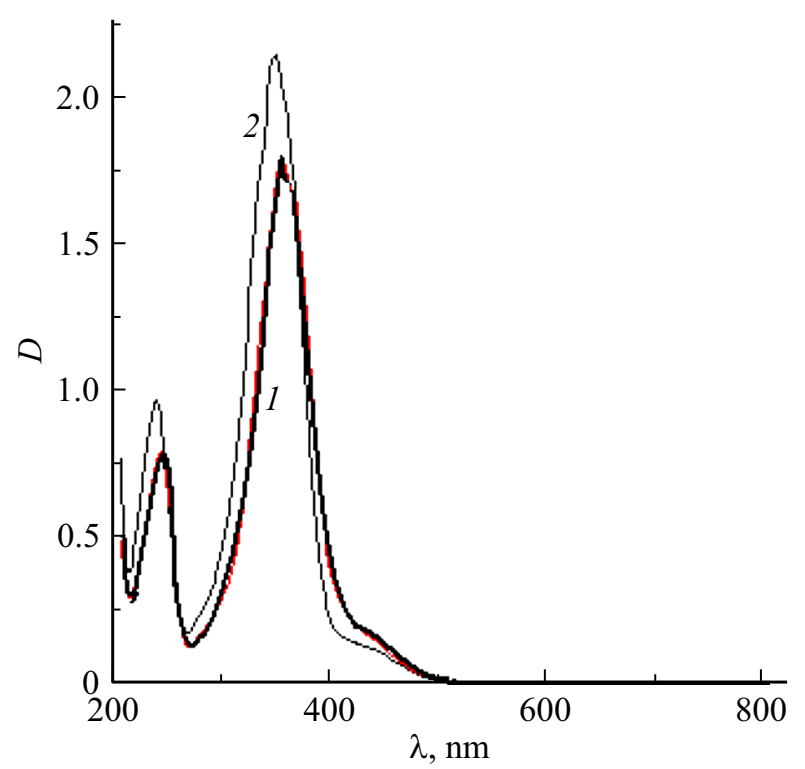

Рис. 1. Спектры поглощения РС с ППК 1 (кривая 1) и $\mathbf{1}^{\prime}$ (кривая 2).

Во всех РС зарегистрированы голограммы плоского волнового фронта как для случая $\mathbf{e}_{1} \| \mathbf{e}_{2}$, так и для случая $\mathbf{e}_{1} \perp \mathbf{e}_{2}$. Основные результаты измерений $\eta_{\| \max }$ и $\eta_{\perp \max }$ и кинетики записи и релаксации голограмм плоского волнового фронта представлены в таблице и на рис. 2. Оказалось, что в группах ППК $\mathbf{1}-\mathbf{3}$ и $\mathbf{1}^{\prime}-\mathbf{3}^{\prime}$ эти основные результаты подобны, но отличаются от результатов для $\mathbf{4}$ и $\mathbf{4}^{\prime}$.

В исследованных РС $\eta_{\perp \max }>\eta_{\| \max }$, что ранее обнаружили для РС на основе других азобензолсодержащих полимеров. Особенностью зависимости $\eta_{\|}(t)$ и $\eta_{\perp}(t)$ является наличие как минимум двух участков кинетики: быстрого и замедленного. После начала экспонирования голограммы величины эффективности $\eta_{\|}(t)$ и $\eta_{\perp}(t)$ быстро нарастают, а затем это нарастание замедляется. Такая же закономерность наблюдается и после выключения одного из записывающих лучей. Однако время записи и хранения голограммы значительно увеличивается при переходе от РС с ППК 1-3 и $\mathbf{1}^{\prime}-\mathbf{3}^{\prime}$ к $\mathbf{4}$ и $\mathbf{4}^{\prime}$. При этом кинетические кривые и время релаксации голограмм остаются такими же, как на рис. 2, если после записи оба записывающие луча выключены. Последнее указывает на то, что один из записывающих лучей, который используется для восстановления голограммы после ее записи, не является стирающим для этой же записи.

Известно [4-7], что при $T_{s}$, которые близки к комнатной температуре, механизм записи поляризационных голограмм с большим временем их релаксации (хранения) связан с тем, что под действием линейно поляризованного света из области поглощения изомеров азобензольного хромофора происходит транс-цис-изомеризация азобензольных фрагментов и перестройка полимерной матрицы. Именно эта перестройка полимерной матрицы 

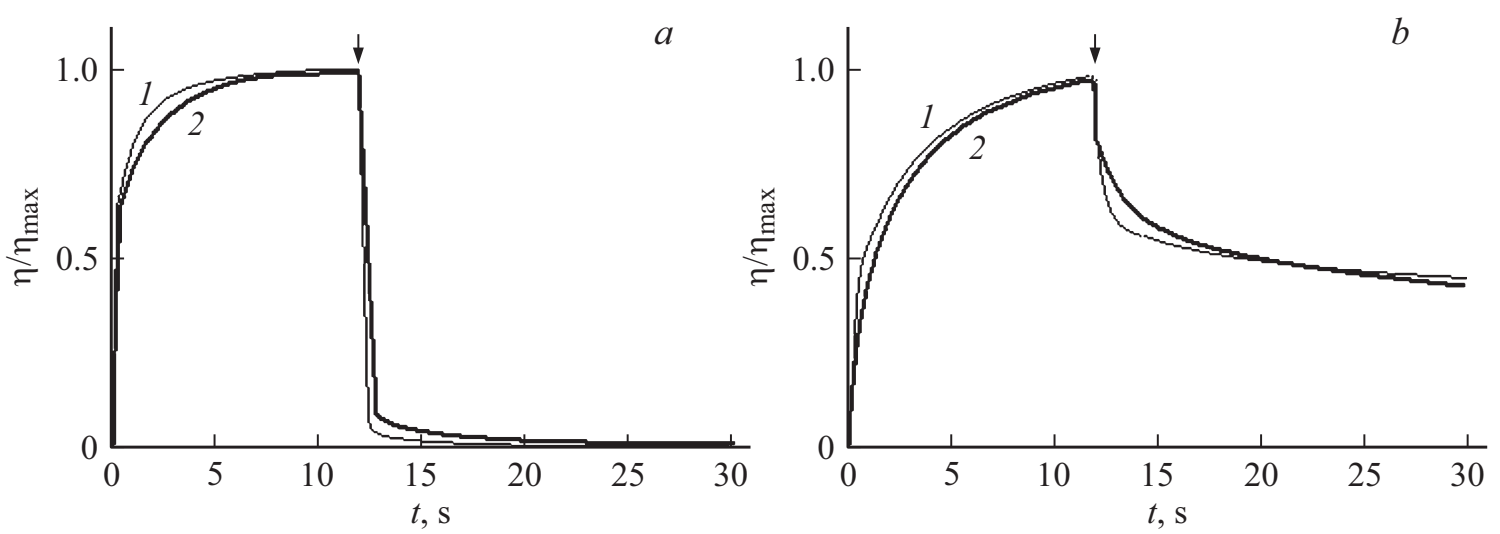

Рис. 2. Графики зависимости $\eta_{\|}$(кривые 1$)$ и $\eta_{\perp}($ кривые 2$)$ от $t$ в образцах РС с ППК $\mathbf{1}^{\prime}(a)$ и $\mathbf{4}^{\prime}(b)$ после начала $(t=0)$ записи голограммы и выключения объектного луча (момент выключения объектного луча отмечен вертикальной стрелкой, направленной вниз).

$a$
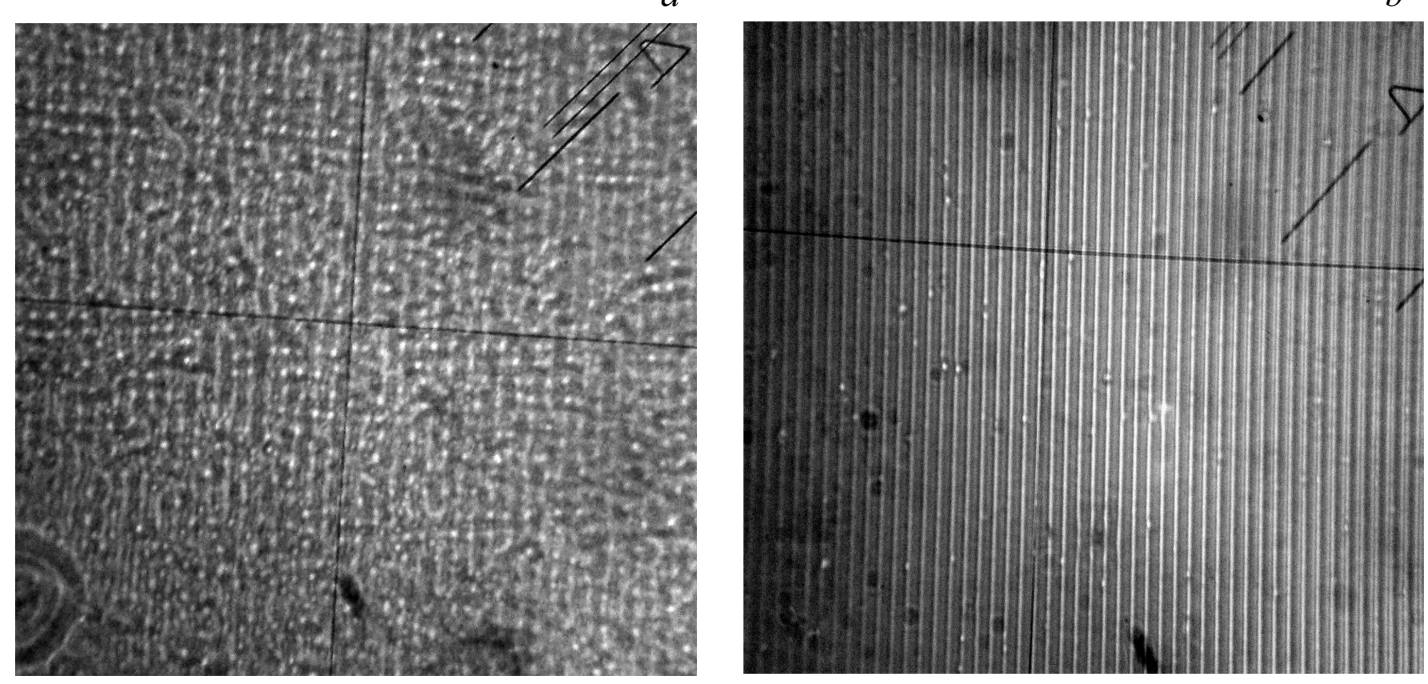

Рис. 3. Фотографии участка поверхности ППК $\mathbf{1}^{\prime}(a)$ и $\mathbf{4}^{\prime}(b)$ в образцах РС, полученные с использованием интерференционного микроскопа МИИ-4 спустя 1 min после экспонирования голограммы (в случае $\mathbf{e}_{1} \perp \mathbf{e}_{2}$ ) в течение $2 \mathrm{~min}$.

ответственна за длительное хранение записи голограмм, что имеет место для РС с ППК 4 и $\mathbf{4}^{\prime}$. При $\mathbf{e}_{1} \| \mathbf{e}_{2}$ и $\mathbf{e}_{1} \perp \mathbf{e}_{2}$ азобензольные группы, участвующие в фотоизомеризации, ориентируются в соответствующих направлениях и появляются дополнительные деформирующие силы, действующие на основную полимерную цепь, что приводит к формированию геометрического рельефа поверхности ППК. Это подтверждается фотографиями поверхности ППК $\mathbf{4}^{\prime}$ на рис. $3, b$ после экспонирования голограммы плоского волнового фронта в случае $\mathbf{e}_{1} \perp \mathbf{e}_{2}$. Так как залечивание рельефа поверхности пленки происходит более медленно, чем релаксация скрытого голографического изображения в поляризационно чувствительных РС, то наличие такого рельефа в целом увеличивает время релаксации $\eta$. Подобные структуры на поверхности ППК образуются при записи рельефных амплитудных голограмм фототермопластическим спосо- бом на фотопроводящих полимерных пленках $[25,26]$ и однородность таких структур обеспечивает высокие информационные характеристики РС и длительное хранение голографической записи. В случае РС с ППК 4 и $\mathbf{4}^{\prime}$ это может быть основной причиной большой величины $\eta_{\perp \max }, \eta_{\| \max }$ и времени хранения голограмм (рис. 2, $b$ и $3 b$ ).

Однако в РС с ППК 1-3 и $\mathbf{1}^{\prime}-\mathbf{3}^{\prime}$ наблюдаются только быстрые процессы записи и релаксации голограмм. Так как в этих ППК нет излучательной диссипации энергии фотовозбуждения азохромофоров (люминесценция ППК отсутствует), то за время экспонирования голограммы поглощенная энергия света расходуется только на транс-иис-изомеризацию азобензольных фрагментов, а остаток поглощенной энергии не достаточен для перестройки полимерных цепей из-за отсутствия ковалентных связей азохромофоров с ними. Поэтому затруднено 
образование устойчивого рельефа поверхности ППК (рис. $3, a)$. Таким образом, быстрый и симметричный характер кинетики записи и релаксации голограмм можно пояснить чисто поляризационной природой формирования ФИА и малым вкладом образования рельефа поверхности ППК. Последнее применимо к объяснению того экспериментального факта, что для РС с ППК 1$\mathbf{3}$ и $\mathbf{1}^{\prime}-\mathbf{3}^{\prime}$ значения $\eta_{\perp \max }$ и $\eta_{\| \max }$ и время записи и релаксации голограмм меньше по сравнению с такими же параметрами для ППК $\mathbf{4}$ и $\mathbf{4}^{\prime}$ (таблица). Хотя и незначительное, но все-таки увеличение $\eta_{\perp \max }$ и $\eta_{\| \max }$ наблюдается при переходе от ППК 1-3 к ППК $\mathbf{1}^{\prime}-\mathbf{3}^{\prime}$ (таблица). Это неожиданно, так как молекулы azo- $\mathrm{OCH}_{3}$ в 1-3 имеют несколько больший дипольный момент в сравнении с azo- $\mathrm{CH}_{3}$ в $\mathbf{1}^{\prime}-\mathbf{3}^{\prime}$, в спектрах поглощения наблюдается слабый батохромный сдвиг при переходе от azo- $\mathrm{CH}_{3}$ к azo-OCH $\mathrm{OCH}_{3}$ (рис. 1), и, согласно [27], при этом должны были бы увеличиваться величины $\eta_{\perp \max }$ и $\eta_{\| \max }$. Такое противоречие можно пояснить стерически-

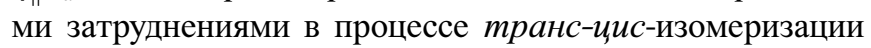
молекул по сравнению azo- $\mathrm{OCH}_{3}$ и azo- $\mathrm{CH}_{3}$. Также отметим, что величина $\eta_{\perp \max }$ и $\eta_{\| \max }$ мало отличается для РС с ППК 1-3 и $\mathbf{1}^{\prime}-\mathbf{3}^{\prime}$ (таблица). Это означает, что для исследованных полимерных матриц, у которых значения $T_{s}$ мало отличаются, процессы транс-цис-изомеризации молекул азокрасителей имеют практически одинаковую эффективность.

\section{Выводы}

Результаты экспериментальных исследований позволяют сделать вывод, что для динамической поляризационной голографии предпочтительны полимерные композиты, в которых хромофоры химически не связаны с полимерными цепями. Естественно, что для образования устойчивых рельефов поверхности полимерных пленок, напротив, следует использовать вещества, у которых хромофоры химически связаны с полимерными цепями. Полученные результаты представляют практический интерес при разработке и создании новых регистрирующих сред для поляризационной и, в частности, для динамической голографии.

\section{Конфликт интересов}

Авторы заявляют, что у них нет конфликта интересов.

\section{Список литературы}

[1] Bian S., Williams J.M., Kim D.Yu., Li L., Balasubramanian S., Kumar J., Tripathy S. // J. Appl. Phys. 1999. V. 86. N 8. P. 4498.

[2] Барачевский B.A. // Опт. и спектр. 2018. Т. 124. № 3. C. 371; Barachevsky V.A. // Opt. and Spectrosc. 2018. V. 124. N 3. P. $373-407$.
[3] Давиденко Н.А., Давиденко И.И., Кравченко В.В., Маринин А.И., Мокринская Е.В., Павлов В.А., Тарасенко В.В., Чуприна Н.Г. // Опт. и спектр. 2019. Т. 126. № 2. C. 197-202.

[4] Priimagi A., Shevchenko A.J. // Polymer Sci. Part B: Polymer Phys. 2014. P. 163.

[5] Davidenko N.A., Davidenko I.I., Pavlov V.A., Chuprina N.G., Tarasenko V.V., Studzinsky S.L. // J. Appl. Phys. 2017. V. 122. P. $013101-1-6$.

[6] Natansohn A., Rochon P. // Chem. Rev. 2002. V. 102. N 11. P. 4139.

[7] Simonov A.N., Uraev D.V., Kostromin S.G., Shibaev V.P., Stakhanov A.I. // Laser Physics. 2002. V. 12. P. 1294.

[8] Emoto A., Uchida E., Fukuda T. // Polymers. 2012. V. 4. P. 150.

[9] Garrot D., Lassailly Y., Lahlil K., Boilot J.P., Peretti J. // Appl. Phys. Lett. 2009. V. 94. P. $033303-1-3$.

[10] Zhou J., Yang J., Ke Y., Shen J., Zhang Q., Wang K. // Optical Materials. 2008. V. 30. P. 1787.

[11] Häckel M., Kador L., Kropp D., Schmidt H.-W. // Adv. Mater. 2007. V. 19. P. 227.

[12] Davidenko N.A., Davidenko I.I., Pavlov V.A., Chuprina N.G., Kravchenko V.V., Tarasenko V.V., Studzinsky S.L., Mokrinskaya E.V., Tonkopieva L.S. // Optik. 2018. V. 158. P. 1308.

[13] Davidenko N.A., Davidenko I.I., Pavlov V.A., Chuprina N.G., Mokrinskaya E.V., Tarasenko V.V., Tonkopieva L.S., Kravchenko V.V. // Optical Materials. 2018. V. 76. P. 169.

[14] Nikolova L., Ramanujam P.S. Polarization Holography. Cambridge, UK: Cambridge University Press, 2009.

[15] Yoshimura T. Thin-Film Organic Photonics: Molecular Layer Deposition and Applications. Boca Raton-London-NY:: CRC Press, 2011.

[16] Naydenova I. (Ed.). Holograms - Recording Materials and Applications. Intech: Rijeka, Croatia, 2011.

[17] Романов О.Г., Горбач Д.В., Толстик А.Л. // Опт. и спектр. 2013. T. 115. № 3. C. 383.

[18] Kabanov V.V., Rubanov A.S., Tolstik A.L., Chaley A.V. // Opt. Commun. 1989. V. 71. N 3-4. P. 219.

[19] Толстик А.Л. Многоволновые взаимодействия в растворах сложных органических соединений. Минск, 2002.

[20] Жаркова Г.М., Стрельцов С.А., Хачатурян В.М. // Жидкие кристаллы и их практическое использование. 2013. T. 1. C. 28.

[21] Шибаев В.П., Бобровский А.Ю. // Успехи химии. 2017. T. 86. C. 1024.

[22] Венедиктов В. // Фотоника. 2016. Т. 55. № 1. С. 132.

[23] Schwetlick $K$. Organicum. WILEY- VCH Verlag GmbH, D69469 Weinheim, 2001.

[24] Collier R.J., Burckhart C.B., Lin L.H. Optical Holography. NY., London: Academic Press, 1973.

[25] Davidenko N.A., Davidenko I.I., Pavlov V.A., Chuprina N.G., Kravchenko V.V., Kuranda N.N., Mokrinskaya E.V., Studzinsly S.L. // Applied Optics. 2018. V. 57. N 8. P. 1832.

[26] Davidenko N.A., Davidenko I.I., Ishchenko A.A., Kudinova M.A., Mokrinskaya E.V., Pavlov V.A., Chuprina N.G. // Theoretical and Experimental Chemistry. 2018. V. 54. N 5. P. 316.

[27] Davidenko N.A., Davidenko I.I., Mokrinskaya E.V., Pavlov V.A., Studzinsky S.L., Tarasenko V.V., Tonkopieva L.S., Chuprina N.G. // Theoretical and Experimental Chemistry. 2017. V. 53. N 2. P. 100. 